\title{
Assessing Willingness to Accept Compensation and Willingness to Pay for Kipkunur Forest Ecosystem Conservation in Elgeyo Marakwet County, Kenya
}

\author{
Silah Kiplimo Misoi ${ }^{1,}$, , Joel Sumukwo ${ }^{1}$, Paul Okello Odwori ${ }^{2}$ \\ ${ }^{1}$ Department of Applied Environmental Social Science (Environmental Economics), University of Eldoret, Eldoret, Kenya \\ ${ }^{2}$ Department of Applied Economics, University of Eldoret, Eldoret, Kenya
}

Email address:

kimi_12@hotmail.com(S. K. Misoi)

${ }^{*}$ Corresponding author

\section{To cite this article:}

Silah Kiplimo Misoi, Joel Sumukwo, Paul Okello Odwori. Assessing Willingness to Accept Compensation and Willingness to Pay for Kipkunur Forest Ecosystem Conservation in Elgeyo Marakwet County, Kenya. International Journal of Economy, Energy and Environment. Vol. 4, No. 5, 2019, pp. 88-95. doi: 10.11648/j.ijeee.20190405.11

Received: August 26, 2019; Accepted: September 19, 2019; Published: October 9, 2019

\begin{abstract}
Public forests provide a variety of goods and services to communities whose opportunity cost is related to the value of alternative goods and services. This study sought to assess expressed conservation value of Kipkunur forests stock flow among economic units using expressed willingness to accept compensation and to pay. In order to account for forest goods and ecosystem services, information sought on forest resources was obtained from households living near the forest. Structured questionnaires were designed for the upstream and downstream households. In administering questionnaires, a systematic random sampling technique was employed and total samples of 224 and 231 for upstream and downstream households were selected, respectively. Excel and Statistical Package for Social Sciences (SPSS version-20) was used in analysis. From the results, there were more females than males in upstream than downstream and more males in downstream than females with the mean age of respondents being 44.47 and 43.42 years, respectively. Again, both study areas depicted mean households' size of 6 persons. Major economic activity for upstream was agriculture, while for downstream were depended on formal jobs and entrepreneurial ventures owed to high education level among households heads. Further, study results showed upstream households expressed high conservation value for the selected forest attributes of fuelwood, water supply, food supply and biodiversity than downstream forests resources, which was seen to be influenced by satiation effect. In conclusion, existences of variation on expressed willingness to conserve for specific forest attributes was influenced by satiation effect. It is recommended for the formulation of policy incentives that corrects redistribution imbalance in resources conservation among economic units in order to reflect Kaldor-Hicks compensation tests.
\end{abstract}

Keywords: Forests Stock Flow, Forests Attributes, Conservation Value, Satiation Effect

\section{Introduction}

Forests generate variety of economic products and services that are critical in supporting livelihoods for households living adjacent and far beyond [1]. Historically, forests are vital to global economy by influencing patterns of rains, providing consumable products and in helping to structure economic development of countries by providing transformable raw material for sustainable growth [2]. Further, forests provides subsistence and income to 350 million people living adjacent to the forest. While estimated proportion of about 20 to $25 \%$ for rural people derive their incomes directly from forest resources which invariably acts as an insurance during prolonged droughts. Therefore, forests existences are of great significance to human life.

Forests often exhibit free riding characteristics due to nonexcludable and non-rivalry of its products and functions to the consumers [4]. Therefore, unrestricted access to forest goods and services abets haphazardly harvesting of consumptive forests commodities and overconsumption [3]. The consequences are the depletion of forest cover which reduces sequestration capabilities on greenhouse gasses such 
as carbon dioxide resulting into climatic episodes [5]. Other effects includes decrease in the flow of forest services to dependable consumers of forests products which puts their livelihoods at perilous state [6].

Africa's forest cover which is estimated to stand at 674 million hectares, decreased from the initial 749 million hectares in the year 2010, with the forest loss being attributed mainly to high demand for domestic and industrial use [7]. This reflects worsening trends in forests cover depletion, if conservation measures are disregarded. The stock flow of forests products depend on stability of forest cover which is achieved through conservation by local communities, however disincentives to forests resource providers tend to encourage rapid degradation of forests particularly in the developing countries [7, 8]. Environmental economists believe that market failure occur when forests services are supplied to the economic units for free by forests providers resulting to negative impact on conservation efforts.

Over the years, researchers have found specific forests attributes to be more relied for livelihood sources by forests consumers than others, thus, inform the need to determine more dependable forests attributes in order to form the forum for negotiating conservation rewards in conservation realm [9]. In order to develop economic incentives tools that reflects lindhal financing scheme as a strategy of attaining sustainable forests cover, determination of economic value based on specific forests attributes is needed. The focus in this study was to evaluate the consistency of economic value of specific forests attributes of fuel wood, food supply, water supply and biodiversity using random utility model with constructs of neoclassical economic theory. The exhibited economic value that described each forests attributes was expressed willingness to accept compensation (WAC) and willingness to pay (WTP) value among economic units [10].

Neoclassical economic theory describes utility in a quasiconcave with respect to consumptive desirables of households or equivalent, whereby the choice and preference of specifying WAC and WTP value for each specific forests attributes if displayed using indifferent curve are convex to the origin [11]. Expressed WAC and WTP value for specific forests attributes implies that consumers of forests commodities are willing to make substitution among available forests goods and services subject to other underlying utilities levels from each attributes.

Therefore, each forests attributes can be expressed in Random Utility Model (RUM) as;

$$
\mathrm{U}_{\mathrm{ij}}=f\left(\mathrm{x}_{\mathrm{ij}}\right)
$$

Where; $U_{i j}$ is the maximum utility $(i)$ derived from forests attributes $(j)$ by forests consumers, while $x_{i j}$ is the expressed utility $(i)$ from specific forests attributes $(j)$ of fuel wood, food supply, water supply and biodiversity.

RUM was derived from choice contingency modelling where forests resource consumers' trade-off between consumption of forests commodities for conservation contribution on each specific forests attributes [12]. In context to this study, economic units $(i)$ were expected to make a choice based on each forest attributes (j) to express their conservation contribution by foregoing consuming forests resources $((\mathrm{k})$ - being willing to be compensated or accepting to pay some amount for conservation) expressed in an equation function as;

$$
P_{i j}=\operatorname{prob}\left(U_{i j}>U_{i k}\right) ; \mathrm{j} \neq \mathrm{k} \text { and } \mathrm{j}>\mathrm{k}
$$

Where; $P_{i j}$ represent the probabilities among economic units in making a choice to conserve each specific forests attributes $(j) ; U_{i j}$ represent preference by expressing conservation efforts of either WAC or WTP among economic units; $U_{i k}$ represent consumers unwillingness to conserve by not expressing any amount of WAC and WTP value.

Therefore, equation 2 in the conceptualised RUM in context to this study, represent the probability based on each attribute by resource consumer. Thus, the main objective of this study was to determine economic value based on expressed WAC and WTP value for specific forests attributes. The variances in each forests attributes could inform aspiration and the level at which resource consumers can contribute towards forest conservation stewardships. This is in view of the fact that Kenya is among the countries that faces forestry degradation menace and the need to reverse the trend through economic incentives is required. Kenya's vision 2030 recognises environmental protection especially forests as a driver that will make the realisation of the government's set blue prints such as water availability, food security and source of raw material for industries. Again, it could solve the puzzle that surround climatic change and alleviation of poverty among population that are heavily dependent on forests commodities and its ecosystem functions.

\section{Material and Methods}

\subsection{Study Area}

This study was done between the months of February and April of the year 2019 in two counties namely Uasin Gishu and Elgeyo Marakwet counties as downstream and upstream study areas, respectively. The geographical location of the downstream study area lies between $0^{0} 30^{\prime}$ North and $0^{\circ} 53^{\prime}$ North and $35^{\circ} 20^{\prime}$ East and $35^{\circ} 35^{\prime}$ 'East, while upstream study area lies between $0^{\circ} 24^{\prime}$ 'and $0^{\circ} 59^{\prime}$ North and $34^{\circ} 07$ and $35^{\circ} 23$ East, respectively (Figure 1). The downstream study area is characterised by flat landscape, while upstream exhibit undulating topography. The altitudes differs where downstream lies at about 1200 and upstream at 2000 metres above sea level, respectively. Since upstream and downstream lies in similar weather zones, the mean annual rainfall is about $1000 \mathrm{~mm}$ with a pattern showing bimodal type of rainfall. The long rains starts between March and August, whereas short rains are from September to November with slight or no rainfall in December. The temperatures varies at the range between $14^{\circ} \mathrm{C}$ and $24^{\circ} \mathrm{C}$ where the upstream experience low temperatures than downstream due to altitude effects. The major economic activities at upstream which is rural based is mixed farming, while downstream which is characterised by urban set up was business ventures. 


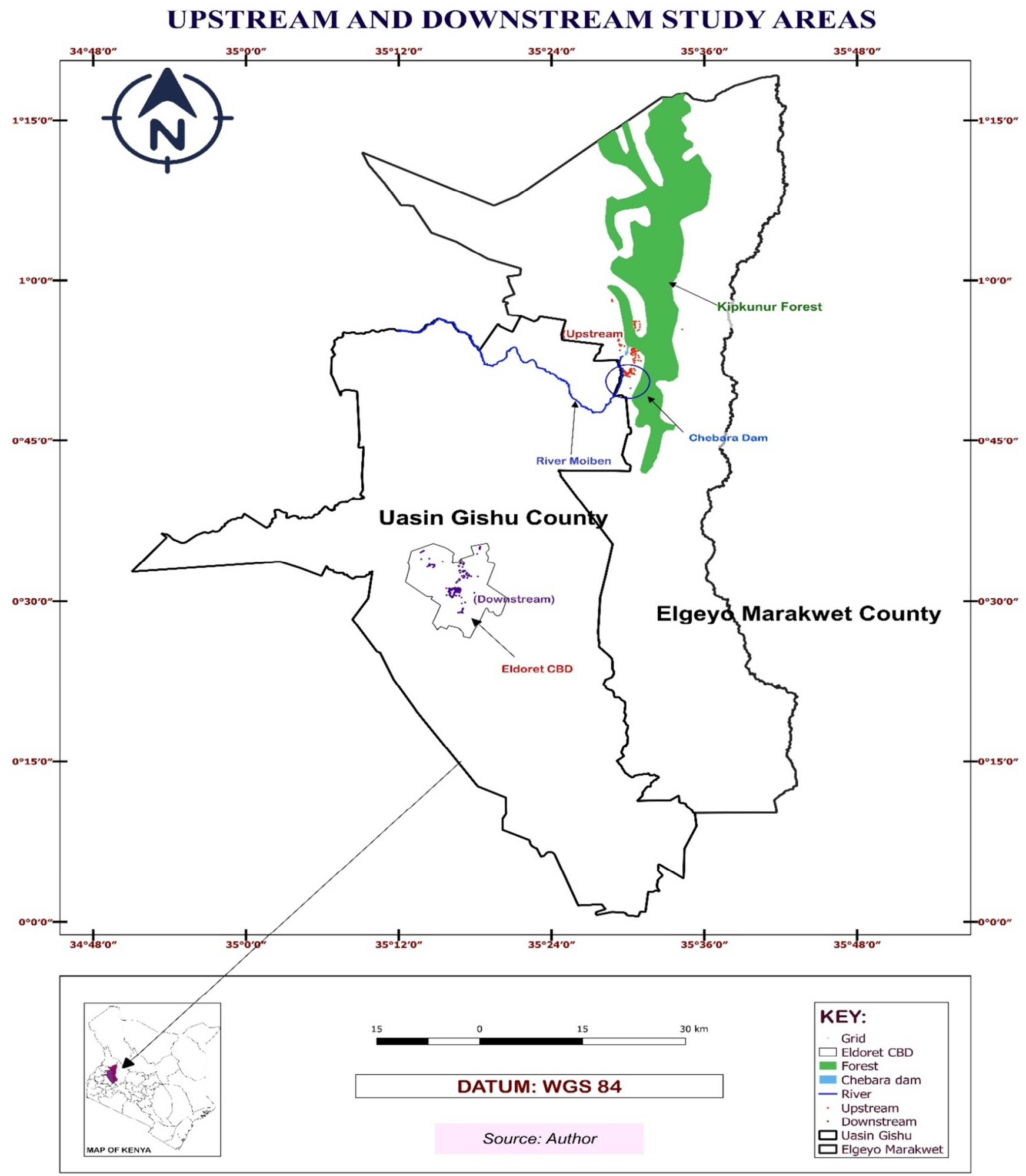

Figure 1. A Map of the Study Area.

\subsection{Data Collection Tool, Sample and Sampling Procedures}

Households' questionnaires was the main data collection tool used to obtain primary information in this study. Other information deemed relevant for this study was sought from documented literatures as secondary data sources. In order to give equal chances in selecting respondents in obtaining primary data, random selection was observed with inclusion criteria where upstream study area was households that lived within a $4 \mathrm{~km}$ range from the edge of Kipkunur forest, while selection of respondents at downstream study area was 
randomly selected within the jurisdiction of Eldoret Municipality. After sample units were identified based on exclusion criterion of distance and study scope jurisdiction for upstream and downstream study areas respectively, systematic random sampling was observed in administering the questionnaires.

To achieve systematic random sampling, reference points from a noticeable physical structures such as a school, a junction and/or a cattle dip was chosen, where the immediate households at the left hand side was selected as first respondent. The subsequent households selected followed the left hand rule method where the third household was chosen until representative samples needed was exhausted. If the samples remained unexhausted, enumerator went back to the reference point and take the left path or route and follows systematic random format. The sample size required for both upstream and downstream was determined using sample size formula as follows;

$$
\mathrm{n}=\frac{\mathrm{NC}^{2}}{\mathrm{C}^{2}+(\mathrm{N}-1) \mathrm{e}^{2}}[13]
$$

Where; $\mathrm{n}$ represent sample size, $\mathrm{N}$ is population size, $\mathrm{C}$ is coefficient of variation at (30\%), confidence limit at (95\%), while $e$ was the standard error at $2 \%$.

To determine the sample size from the formula in equation 3 , the target population for upstream and downstream was necessary. Based on [14] data the households population which was the target population for downstream was 9584, while for upstream was 3241 respectively. Therefore, the calculated sample size from the formula was as follows;

Determination of upstream sample size

$$
\mathrm{n}=\frac{3241\left(0.3^{2}\right)}{0.3^{2}+(3241-1) 0.02^{2}}
$$

$$
\begin{gathered}
n=\frac{291.69}{1.386} \\
n=211
\end{gathered}
$$

Determination of downstream sample size

$$
\begin{gathered}
\mathrm{n}=\frac{9584\left(0.3^{2}\right)}{0.3^{2}+(9584-1) 0.02^{2}} \\
\mathrm{n}=\frac{862.56}{3.9232} \\
\mathrm{n}=220
\end{gathered}
$$

To compensate unclearly explained, missing and erroneously entered information in the questionnaires by respondents in a questionnaires which invalidates the findings, additional questionnaire that represent $10 \%$ was provided. Therefore, the total questionnaires administered for downstream and upstream were 231 and 224, respectively.

Further, to capture contingent Choice Model approach, hypothetical questions in households' questionnaire were formulated which asked randomly selected respondents to bid and state WAC value for upstream forests users and WTP value for downstream for conservation of specific forests attributes. The forest attributes for this study offered for bidding were fuelwood, water supply, food provision and biodiversity conservation where WAC reflects resource providers who are losers through conservation, while WTP

\begin{tabular}{|c|c|c|c|c|c|c|}
\hline \multirow{2}{*}{ Variables } & \multicolumn{3}{|l|}{ Upstream } & \multicolumn{3}{|l|}{ Downstream } \\
\hline & Frequency & Mean & S. D. & Frequency & Mean & S. D. \\
\hline Age & $224(100 \%)$ & 44.47 Years & 12.81 & $233(100 \%)$ & 43.42 Years & 10.51 \\
\hline Male & $103(46 \%)$ & - & - & $137(58.8 \%)$ & - & - \\
\hline Female & $121(54 \%)$ & - & - & $96(41.2 \%)$ & - & - \\
\hline Household size & $224(100 \%)$ & 5.95 Members & 2.21 & $233(100 \%)$ & 5.20 Members & 1.87 \\
\hline Farmer & $195(87.1 \%)$ & - & - & $150(64.4 \%)$ & - & - \\
\hline Business & $28(12.5 \%)$ & - & - & $52(22.3 \%)$ & - & - \\
\hline Civil Servant & $1(0.4 \%)$ & - & - & $29(12.4 \%)$ & - & - \\
\hline Informal Jobs & $0(0.0 \%)$ & - & - & $2(0.9 \%)$ & - & - \\
\hline
\end{tabular}
represent resource consumers who are gainers deriving forests stock flow benefits without or with minimal costs. Further, the means values of parameters identified in this study that describes respondents' conservation aspiration in regards to specific forests attributes conservation was used.

Table 1. Households Socio Economic Characteristics for Upstream and Downstream Study Areas.

Source: Author; $\mathrm{n}=224$ (upstream), 233 (downstream) respectively; Freq = frequency; \% = Percentages; S. D. = Standard Deviation

\section{Study Results}

\subsection{Socio Economic Characteristics}

Table 1 illustrate households' socio economic variables of age, gender, households' population, households' head occupation and years in formal education that was used to describe households' characteristics in this study areas. The construct of age for upstream and downstream households' heads had almost the same average ages of 44.47 and 43.42 years, respectively. While the mean household size in both upstream and downstream were similar of 6 members per household. However, the variable of gender exhibited variances where females were found to be more at upstream 
than at downstream at $121(54 \%)$ and 96 (41.2\%), respectively. Again, the number of males respondents in downstream showed to be more than upstream at 137 (58.8\%) and 103 (46\%) respectively. Further, upstream study area which was rural based showed to have more females than males and vice versa on downstream area which was urbanised. The occupation that mostly supports upstream livelihood was agricultural activities at 195 (87.1\%), while proportion of households that engaged in business ventures and formal employments were $28(12.5 \%)$ and $1(0.4 \%)$, respectively. There was no presence of informal jobs rather mixed farming in upstream study area. However, at downstream study area households were seen to derive their livelihoods majorly by engaging in farming, despite being regarded as commercial hub for business venture, formal and informal jobs at $150(64.4 \%), 52(22.3 \%), 29(12.4 \%)$ and 2 $(0.9 \%)$, respectively.

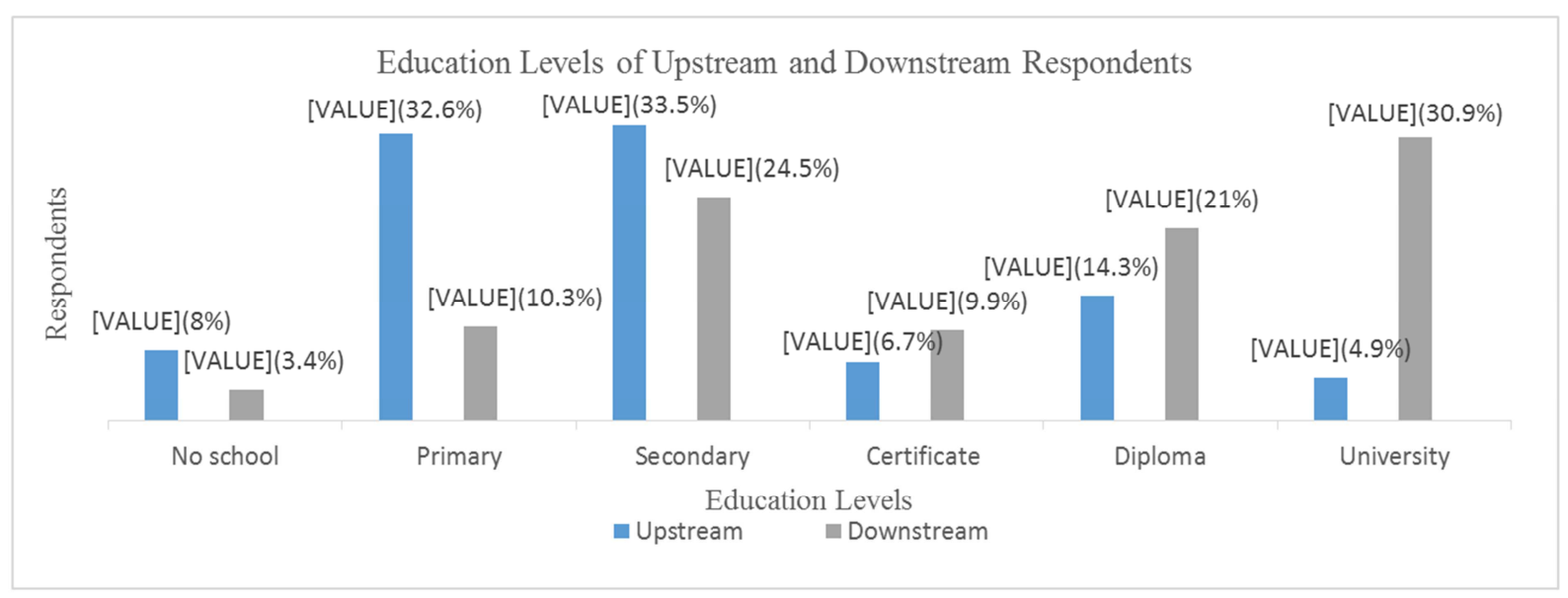

Source: Author. Note: Values depicted in the graph are percentage means of frequencies of respondents

Figure 2. Education levels of upstream and downstream households.

In regards to education level, results showed that majority of household heads in upstream had attained basic education at $73(33 \%)$ primary and $75(34 \%)$ secondary education levels, while $15(6.7 \%)$ had certificate, 32 (14.3\%) had diploma and 11 (4.9\%) had university advanced education levels, respectively. Households heads with no education level at upstream were $18(8 \%)$ with majority found to be elderly persons. Whereas in the downstream, majority of households heads had higher education compared with upstream study area at $72(30.9 \%)$ university, $49(21 \%)$ diploma, 57 (24.5\%) secondary, $23(9.9 \%)$ certificate and 24 $(10.3 \%)$ primary levels, respectively, while $8(3.4 \%)$ had no schooling (Figure 2).

\subsection{Ecosystem Values}

Table 2 shows means of expressed WAC and WTP values for the conservation of specific forests attributes by upstream and downstream resource consumers respectively.

Table 2. Expressed WAC and WTP Values for the Selected Kipkunur Forests Attributes.

\begin{tabular}{llllll}
\hline \multirow{2}{*}{ Forests Attributes } & Upstream & & & Downstream \\
\cline { 2 - 6 } & Mean WAC & SD & S. E & Mean WTP & SD \\
\hline Fuel Wood & 10675.00 & 20591.56 & 1375.83 & 1275.07 & 16375.52 \\
Water Supply & 17757.59 & 75576.27 & 5049.65 & 308.49 & 278.57 \\
Food Supply & 15756.25 & 38739.25 & 2588.37 & 3952.42 & 41072.80 \\
Biodiversity & 21908.04 & 102522.01 & 6850.04 & 8730.17 & 28.37 \\
\hline
\end{tabular}

Source: Author. Note: SD = Standard deviation, S. E = Standard Error

From the results, the expressed WAC values by upstream households revealed high values compared with the WTP values by downstream resource consumers. Further from the results, the standard deviation of WAC and WTP values on selected forests attributes showed higher values except WTP values of forests attributes on water and food supply, while standard error for WAC was higher if compared with that of WTP value.

When ratios of WAC and WTP values of each specific forests attributes was determined, the results showed different variation (Table 3). From the results, forests attributes of water supply showed high difference in amount expressed for conservation at about 58 times, while fuel wood, food supply and biodiversity showed variation of 8.87 , 3.99 and 2.51 respectively.

Further, figure 3 illustrates differences in expressed economic values from the selected forests attributes of fuel wood, water supply, food provision by the forests and biodiversity by upstream and downstream households. 
Table 3. Result Showing WAC and WTP Ratios.

\begin{tabular}{llll}
\hline Forests Attributes & Mean WAC & Mean WTP & Ratios $=\left(\frac{\text { Mean WAC }}{\text { Mean WTP }}\right)$ \\
\hline Fuel Wood & 10675.00 & 1275.07 & 8.87 \\
Water Supply & 17757.59 & 308.49 & 57.56 \\
Food Supply & 15756.25 & 3952.42 & 3.99 \\
Biodiversity & 21908.04 & 8730.17 & 2.51 \\
\hline
\end{tabular}

Source: Author. Note: $\mathrm{WAC}=$ Willingness to Accept Compensation value; $\mathrm{WTP}=$ Willingness to Pay value

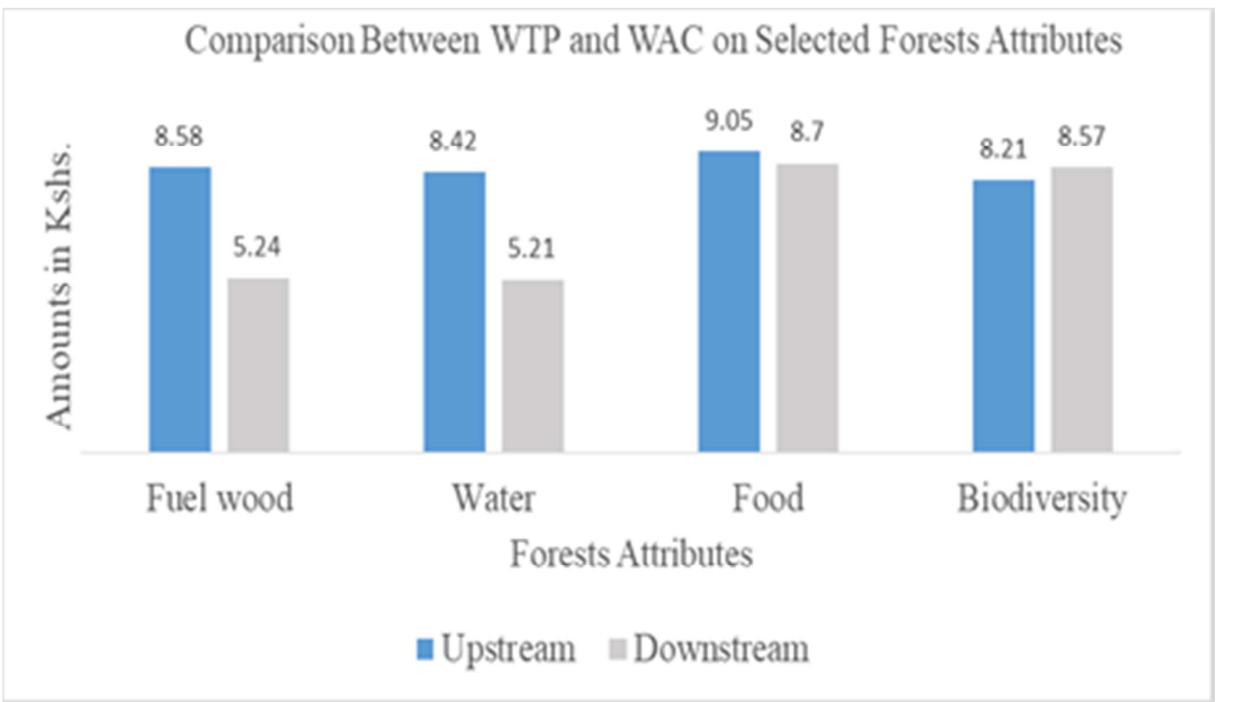

Source: Author. Note; Depicted economic values in the figure was transformed from real values into natural logarithms

Figure 3. A Graph Showing Values of WTP and WAC on the Selected Forests Attributes.

Comparative study results showed that upstream households expressed higher economic values on fuel wood (8.58), water supply (8.42) and Food provisions (9.05) than downstream users at 5.24, 5.21 and 8.70 , respectively. However, the forests attributes of biodiversity showed downstream users expressed higher values at 8.57 than upstream users at 8.21 , respectively.

\section{Discussions}

Existence of more females than males in upstream study area explains the norm in African culture where females often engage in households' chores which makes them to be occasionally found at homes. While downstream study area which depicted more males than females explains further the African set up which regards males as family providers where they often engage in external activities, hence they are unavailable at rural homes. These study findings were in agreement with past studies which found more females than males in rural homes $[15,16]$. Further, this study agree with past research findings that entrepreneurial skills and the norm in African set up regards males as family providers and makes them to move out from rural homes to urban areas leaving females as their wives to tend domestic work [17-19]. The fact that urban areas act as market points with improved infrastructure which enables the flourishing of business ventures, could be the reason that urban areas act as magnet that attracts more educated and skilled persons as depicted by study results of the presence of more educated households heads in urban areas than in rural homes. While construct of age which showed no variance, explains age as non-critical variables in forests resources conservation.

Dependency on agricultural ventures as sources of livelihood in both upstream and downstream study area coupled with big household size as depicted by study results, raises the concerns on natural resource degradation, especially soil components if soil management structures are disregarded such as building of gabions, construction of terraces and planting of vegetation cover to ameliorate soil erosion. Again, existences of low level of education among households in upstream study area raises paradoxical questions on the capabilities of rural homes to comprehend scientific knowledge in regards to resources conservation for sustainability. There is a relationship of household size with forests resources demands [20-23]. As such, it points out the need for prudent and sustainable agricultural practices which can translate to resource conservation in the upstream areas, while, low education level at upstream study area requires the need to upscale access to formal education among rural homes in order to enhance comprehension and implementation of scientific knowledge in resources protection and conservation.

Effect of distance decay was exhibited by difference in economic values of WTP and WAC on attributes of Fuelwood and water, which explains the construct of distances to influence forests resource conservation by adjacent and far beyond communities. In most of ecosystem valuation, WAC values are often higher than WTP values and 
are influenced by non-satiation effects, which are in tandem with the study findings of this research [24]. The most fundamental reasons that influenced low expression of WTP value for forests conservation by downstream users as pointed out by focus group discussion was the inconsistent supply of piped water emanating at upstream study area and cost effect due to distance which makes forests products of water supply and fuel wood costly. These cost effects prompt resources consumers to seek cheap substitutes such as harvested rain water and/or water from unlined households well and cheap sources of energy such as liquefied petroleum gas especially by urban dwellers.

Depicted variation by study results between ratios of expressed WAC and WTP on forests attributes could explains non conformity with Kaldor-Hicks compensation tests. This suggests unequal conservation efforts between resource producer and consumer, thus raising the concerns for the formulation of economic incentives policies to correct the imbalance. The low standard deviation of expressed WTP value on food and water supply was influenced by the market price effect. This was because of the existences of market price on food and water supply from forests as opposed to free riding effect in obtaining such commodity by upstream forests users. Depicted nearly equal expressed conservation values on food supply by adjacent and far beyond forests consumers from study results suggests that that food provisions by forests such as honey, wild fruits and wild vegetable as critical forests products. Since downstream users were found to be more educated than upstream, awareness on the importance of biodiversity conservation based on the acquired scientific knowledge from their formal education could have contributed in expressed higher values despite long distance to the Kipkunur forests. This study findings is in agreement with study results on impacts of education on WTP values [25].

\section{Conclusion}

Specific forests attributes such as regulation, provisions and supportive are critical for human livelihood, however, such services often remain unaccounted in contemporary markets. For this reason, it is important to account based on its economic value. The paradigm shift in this study was to account economic value of forests ecosystem based on its selected ecosystem functions of fuelwood, water supply, food supply and biodiversity as opposed to aggregate valuation of ecosystem functions.

From the study results, upstream study area showed to have more female than male, supporting the norm in African set up where males are perceived as resource providers while females remain as domestic functionaries. Again, more educated respondents were found in downstream study area, hence, formal jobs and entrepreneurial ventures were common source of livelihoods, while upstream was found to rely on agriculture as main economic source. Distance decay was a predominant factor that affected the consumption of forest products among economic units. Further, food supply as forests function was found to act as food security safe nets for upstream users, while downstream was found to seldom rely on such forests products.

Further, expressed WAC value for the conservation of forests resources revealed to be higher than WTP value, suggesting satiation effect in expressed conservation stewardship among economic units. While variance from expressed conservation stewardship between upstream and downstream forests resources users, suggests non-conformity in allocation and redistribution of conservation rewards.

\section{Recommendations}

Reliance of agriculture by upstream households as the mainstay income source coupled with low level of education which increases the propensity for rural homes to degrade environments, calls for policy intervention that enhance access to formal education especially at upstream study area in order to impart scientific knowledge on resource protection and conservation. Again, access to formal education increases the entrepreneurial skills; hence, increasing the chances of income diversification through self-employment through technical and vocational training which is currently being fostered by the government of Kenya is supported.

Further, existence of variance in the selected forests attributes of fuel wood, water supply, food supply and biodiversity in resource protection and conservation between resources providers and consumer, informs the need to formulate taxation policies that allows the consumer of the resource to compensate providers in order to bridge conservation variation gap. Again, formulation of regulation that would restrict free riding effect to forests products, which is informed by study the results, is recommended.

\section{Acknowledgements}

The author thanks respondents in the study area who participated in sharing valuable information that necessitated this study.

\section{References}

[1] Sheil, D. (2018). Forests, atmospheric water and an uncertain future; the new biology of the global water cycle. Sheil Forest Ecosystems, 5 (19), 2-22. Doi: https:/doi.org/10.1186/s40663018-0138-y.

[2] Agrawal, A. C. (2013). United Nations Forum on Forest Tenth Session. Istambul, Turkey; United Nations.

[3] Suleiman, M. S., Wesonga, V. O., Mbau, J. S., Suleiman, A., \& Ehadi, Y. A. (2016). Non-Timber Forest Products and their contribution to household Income around Falgore Game Reserve in Kano, Nigeria. Ecological Process, 1-14.

[4] Cheserek, G. J. (2016). Interface of Community Livelihoods and Environmental Management in Cherangany Forest, Elgeiyo Marakwet County, Kenya. Journal of Environmental Science, Computer Science and Engineering \& Technology, 5 (4), $792-808$. 
[5] Coe, M. T., Mathews, T. R., Greenglass, N. L., Imbuzeiro, H. M., Levine, N. M., Malhi, Y.,... Wang, J. (2013). Deforestation and Climate feedbacks threaten the Ecological Integrity of South-Southeastern. Philosophical Transactions B of Royal Society, 368 (1619), 1-9. Doi: 10.1098/rstb.212.0155.

[6] Caputo, J., Beier, C. M., Luzadis, V. A., \& Groffman, P. M. (2016). Intergarating Beneficiaries into Assessment of Ecosystem Services from Managed Forests at the Hubbard Brook Experimemntal Forest, USA. Forest Ecosystem, 1-15.

[7] Makunga, J. E., \& Misana, S. B. (2017). The Extend and Drivers of Deforestation and Forest Degradation of Masito Ugalla Ecosytsem, Kigoma Region, Tanzania. Open Journal of Forestry, 285-305.

[8] Duguma, L. A., Atela, J., Minang, P. A., Ayana, A. N., Gizachew, B., \& Nzyoka, J. M. (2019). Deforestation and Forest Degaradation as an Environmental Behavior; Unpacking Realities Shaping Communities Actions. Land, 8 (26), 2-17. Doi: 10.3390/land8020026.

[9] Angelsen, A., Jagger, P., Babigumira, R., Belcher, B., Hogarth, N. J., Bauch, S.,... Wunder, S. (2014). Environmental Income and Rural Livelihoods; A Global-Comparative Analysis. World Development, 64, s12-s28. Doi: 10.1016worlddebv.2014.03.006.

[10] Hiligsmann, M., van Durme, C., Geusens, P., Dellaert, B. G., Dirksen, C. D., vander Weijden, T.,... Boonen, A. (2013). Nominal Group Techniques to Select Attributes for Discrete Choice Experiments; An example for Drug Treatment Choice in Osteoporosis. Dove Press Journals, 133-139.

[11] Soufiani, H. A., Parkes, D. C., \& Xia, L. (2012). Random Utility Theory for Social Choice. In Proceedings of the 25th Annual Conference on Neural Information Processing Systems (NIPS'12). 3, pp. 126-134. Lake Tahoe, Nevada; Curran Associates and NIPS

[12] Baltas, G., \& Doyle, P. (2001). Random Utility Models in Marketing Research; A Survey. Journal of Business Research, $21,115-125$.

[13] Kothari. (2004). Research Methodology; Methods \& Technology (2nd ed.). New Dheli, India; New Age International Publishers.

[14] KNBS, \& SID. (2009). Exploring Kenya's Inequality; Pulling Appart or Pooling Together? Nairobi; Kenya National Bureau of Statistics.
[15] Chavanduka, G. (1975). Rural and Urban Life. African eJournal Projects, 4 (ii), 69-78.

[16] UN. (2011). Men in Families and Family Policy in a Changing World. New York; United Nations.

[17] Maruzani, N. (2014). Problems faced by Rural Women in Buhera District of Manicaland South Province of Zimbabwe. Journal of Emerging Trends in Educational Research and Policy Studies (JETERAPS), 5 (3), 370-376.

[18] Sunderland, T., Achdiawen, R., Angelsen, A., Babigumira, R., Ickowitz, A., Paumgarten, F.,... Shively, G. (2014). Challenging Perception about Men, Women and Forest use; A Global Comperative Study. World Development, s56-s66.

[19] Mukoni, M. (2015). Traditional Gender Roles of Men and Women in Natural Resource Conservation among Vhavenda People in Zimbabbwe; Implication for Sustainable Development. International Journal of Humanities and Social Sciences, 5 (4 (i) ), 76-84.

[20] Mmon, P. C., \& Mbee, M. D. (2013). Population Pressure and Forest Resource Depletion in Gele Gele Forest Resource of Eldo Estate, Nigeria. International Journal of Physical and Human Geography, 1 (3), 31-42.

[21] Jain, P., \& Sajjad, H. (2015). Household Dependency on Forest Resources in the Sariska Tiger Reserve (STR), India; Implication for Management. Journal of Sustainable Forestry, 7 (33), 1-15.

[22] Pawar, K., \& Rothkar, R. V. (2015). Forest Conservation and Environmental Awareness. Procedia Earth and Planetary Science, 11, 212-215.

[23] Bennet, N. J., Roth, R., Clain, S. C., Christie, K. P., Clark, D. A., Cullman, G.,... Weyborn, C. (2017). Conservation Social Science; Understanding and Integrating Human Dimensions to Improve Conservation. Biological Conservation, 205, 93-108.

[24] Ibarra, A., Astbury, N. M., Olili, K., Alhoniemi, E., \& Tiihonen, K. (2016). Effects of Polydextrose on Subjective Feelings of Appetide During the Satiation and Satiety Periods; A Systematic Review and Meta-Analysis. Nutrients, 8 (45), 219.

[25] Khan, J. A. (2013). Impacts of Educational Intervention on WTP for Health Insurance; A study of informal sector in urban Bangladesh. Health Economic Review, 3 (12), 2-10. 